\title{
Finite Element Analysis of the thermo-Mechanical Behavior of composite Pipe Elbows under Bending and Pressure loading
}

\author{
E. Abdelouahed \\ Laboratoire LABAB, Ecole Nationale Polytechnique Maurice Audin, Oran, Algeria \\ heabamine@gmail.com
}

\author{
M. Mokhtari \\ Laboratoire LaRTFM, Ecole Nationale Polytechnique Maurice Audin, Oran, Algeria \\ mokbtarimohamed44@yahoo.fr
}

\section{H. Benzaama}

Laboratoire LABAB, Ecole Nationale Polytechnique Maurice Audin, Oran, Algeria

Habenza@yahoo.fr

\begin{abstract}
Elbows under load experience more stress and strain than straight tubes. The strength of the composite tubes plays an important role in their use, the damage under a thermomechanical behavior of a composite tubular structure bent between two linear parts is studied in this work. The HASHIN criterion model is used through finite element analysis. The main objective is to predict the effect of the main parameters by curves of torque, using the calculation code ABAQUS. These evaluative parameters are addressed to the geometrical conditions of the elbow, in loading mode on the pressurized structures and to the danger of the defect, hence the advantage of using Shell elements as a structure. The numerical results obtained illustrate that the parameters studied condition the level and the mode of failure as well as the response of composite elbows.
\end{abstract}

KEYwORDS. FEM; Damage; Elbows; Hashin criterion; Shell element.

\section{OPEN ACCESS}

Citation: Abdelouahed, E., Mokhtari, M., Benzaama, H., Finite Element Analysis of the thermo-Mechanical Behavior of composite Pipe Elbows under Bending and Pressure loading, Frattura ed Integrità Strutturale, 49 (2019) 698-713.

Received: 21.04 .2019

Accepted: 09.06.2019

Published: 01.07.2019

Copyright: (C) 2019 This is an open access article under the terms of the CC-BY 4.0, which permits unrestricted use, distribution, and reproduction in any medium, provided the original author and source are credited.

\section{INTRODUCTION}

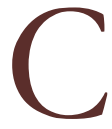
omposite materials used in piping design in industries such as nuclear power plants, oil-gas, energy and environment, are imposed by their operating ranges from $-30^{\circ} \mathrm{C}$ to $120^{\circ} \mathrm{C}$ and 8 at 15 bars. This also depends on chemical constraints such as corrosion. Their normalization remains difficult given these numerous dependencies. Homogenization models remain the appropriate approach to estimate them from these characteristics.

Several important elements in the mechanical analysis of composite materials such as folds that must comply with the surface curvature, dimensioning such as thickness, diameter and radius of curvature have known several international 
standards such as ASME16 .9 [1-3] and the European standard EN 10253- [4] based on experimental tests and analytical calculations. In view of the geometrical configuration of the elbow, the circulating fluid submits it to bending moments. Several researchers are studying the resistance of composite tubes such as Lee et al [5] and Sivakumar Palanivelu et al [6]. They found that its resistance depends on the fiber in its quality, are orientation and its fraction. Research on the combined influence of internal pressure and bending in composite tubular structures has found its way through the work of Natuski et al [7] on the flexural strength of composite tubes. Experimental tests done by Kitching et al [8] on composite bends subjected to bending with and without pressure. A comparison also made by Kochekseraii and. Al. [9] which ends with a good agreement between the experimental and the finite element analysis on a composite tubular structure subjected to a combined loading.

The elbow in its geometric configuration will cause a variation of stress along its intrados and the extrados from where the analytical solutions that are possible to be implemented [10]. Several loading conditions are possible giving rise to several types of damage. The study of these tubular composite structures by thermal effect have taken the interest of other researchers as well, Shao [11] evaluated the thermal stresses as well as Kandil et al. [12] by the numerical model. Others such as Bakaiyan et al [13-16] on composite tube responses to combined internal pressure and thermomechanical loading. By their presence, the defects and the temperature, strongly and geometrically destabilize the bends in their resistance, ex; loading mode or misalignment of fibers or orientation anomalies [17]. Matrix cracking and delamination are the main modes that cause the fiber to break [18] and subsequently lead to complete damage.

In numerical calculation and composites, most researchers are based on two energy methods. The virtual crack closure technique (VCCT) such as the work of Wimmer et al. [19, 20] on initiation and propagation of delamination and cohesive zone method (CZM) by Gözlüklü and Coker $[21,22]$ who studied the same phenomenon. However, other models of damage exist. The one used by Garnish et al [23] proposed by Padhi et al [24] where the structure rigidity vanishes entirely at the beginning of the failure. It is identified according to the failure criteria of Tsai-Wu [25]. Given these numerous advantages, the Hashin criterion [26] is widely used in composite damage [27]. This criterion uses six modes of failure between fiber and matrix and the separation between them [28]; it is presented by ultimate constraints. The purpose of the present work using the Hashin criterion is to predict the damage under internal pressure and temperature of composite tubular structures caused by a bending moment and by the presence of defect in its quality and location as parameter dangerousness.

\section{HASHIN CRITERION AND INPUT PARAMETER}

7 he Hashin criterion is implemented in the standard Abaqus calculation code [29]. The input data given in Tab.(1) are: longitudinal tensile and compressive strengths, transverse tensile and compressive strengths, and longitudinal and transverse shear strengths. All resistance values are assumed to be positive [30]. The damage is continuous in the structure by degradation of rigidity or by removal of the elements. In composites the damage is multimodal, that of fiber and or matrix. In the Hashin criterion, the damage is presented by the following forms:

1. Tensile fiber failure for $\sigma 11 \geq 0$

$$
\left(\frac{\sigma_{11}}{X_{T}}\right)^{2}+\frac{\sigma_{12}^{2}+\sigma_{13}^{2}}{S_{12}^{2}}= \begin{cases}\geq 1 & \text { failure } \\ <1 & \text { no failure }\end{cases}
$$

2. Compressive fiber failure for $\sigma_{11}<0$

$$
\left(\frac{\sigma_{11}}{X_{C}}\right)^{2}= \begin{cases}\geq 1 & \text { failure } \\ <1 & \text { no failure }\end{cases}
$$

3. Tensile matrix failure for $\sigma_{22}+\sigma_{33}>0$

$$
\frac{\left(\sigma_{22}+\sigma_{33}\right)^{2}}{Y_{T}^{2}}+\frac{\sigma_{23}^{2}-\sigma_{22} \sigma_{33}}{S_{23}^{2}}+\frac{\sigma_{12}^{2}+\sigma_{13}^{2}}{S_{12}^{2}}= \begin{cases}\geq 1 & \text { failure } \\ <1 & \text { no failure }\end{cases}
$$

4. Compressive matrix failure for $\sigma_{22}+\sigma_{33}<0$ 


$$
\left[\left(\frac{Y_{C}}{2 S_{23}}\right)^{2}-1\right]\left(\frac{\sigma_{22}+\sigma_{33}}{Y_{C}}\right)+\frac{\left(\sigma_{22}+\sigma_{33}\right)^{2}}{4 S_{23}^{2}}+\frac{\sigma_{23}^{2}-\sigma_{22} \sigma_{33}}{S_{23}^{2}}+\frac{\sigma_{12}^{2}+\sigma_{13}^{2}}{S_{12}^{2}}= \begin{cases}\geq 1 & \text { failure } \\ <1 & \text { no failure }\end{cases}
$$

5. Interlaminar tensile failure for $\sigma_{33}>0$

$$
\left(\frac{\sigma_{33}}{Z_{T}}\right)^{2}= \begin{cases}\geq 1 & \text { failure } \\ <1 & \text { no failure }\end{cases}
$$

6. Interlaminar compression failure for $\sigma_{33}<0$

$$
\left(\frac{\sigma_{33}}{Z_{C}}\right)^{2}= \begin{cases}\geq 1 & \text { failure } \\ <1 & \text { no failure }\end{cases}
$$

The simulations made are more reliable through the use of shell elements because there is no interface between the folds or between the fibers and the matrix. The numerical computation parameters have been in agreement with the computational convergence, which allows us more to go towards the evaluation of the quality of defect. These defects are hardly supported by numerical calculations using other criteria. The parameters introduced in the ABAQUS calculation code are:

\section{** MATERIALS}

$* *$

*Material, name $=$ Material-1

*Damage Initiation, criterion=HASHIN 2050.,1200., 62., 190., 81., 81.

*Damage Evolution, 45., 45., 0.6, 0.6

*Damage Stabilization 0.003,0.003,0.003,0.003

*Elastic, CONSTANTS

170000.,9000.,9000., 0.34, 0.34, 0.34,4800.,4800.4500.,

*Expansion,

$0.1 \mathrm{E}-6,0.1 \mathrm{E}-6,0.1 \mathrm{E}-6$

3. Description of model geometry and material properties

The geometries of the composite structure with these standardized dimensions [31] are illustrated in Fig. (1). These characteristics of elasticity and resistance are reported in Tab.(1): The elbow element is connected to two straight pipes 1100 $\mathrm{mm}$ long. This length is sufficient to ensure that no stress interference in the region of the ends of the elbow will occur. It is assumed that no failure occurs at the straight pipe which should only act as a means of uniformly transferring the bending moments to the bends. Numerically the load of bending moment on the elbow was obtained by imposing a rotation about the axis perpendicular to the plane of curvature of the elbow.

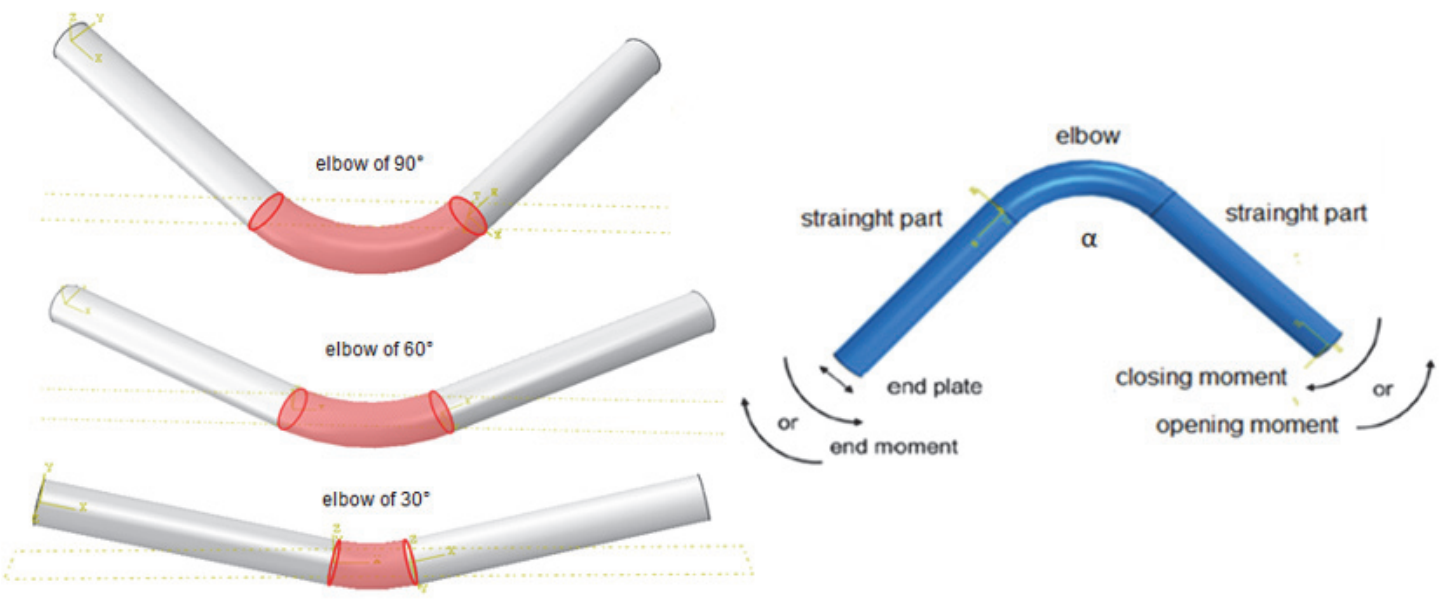

Figure 1: Overview of the studied geometry. 
Composite tubular structures having the following dimensions: a diameter equal to $50 \mathrm{~mm}$ and a thickness equal to $2 \mathrm{~mm}$. The three elbows have the same radius of curvature equal to $20 \mathrm{~mm}$. Only one elliptical defect shape with one dimension is taken for each case. In order to better compare the damage results, these elbows are uniformly subjected to an imposed rotational movement of $60 \circ$. In order to cause only the damage, the defect is always in these three locations in the extrados of the elbow Fig. (5).
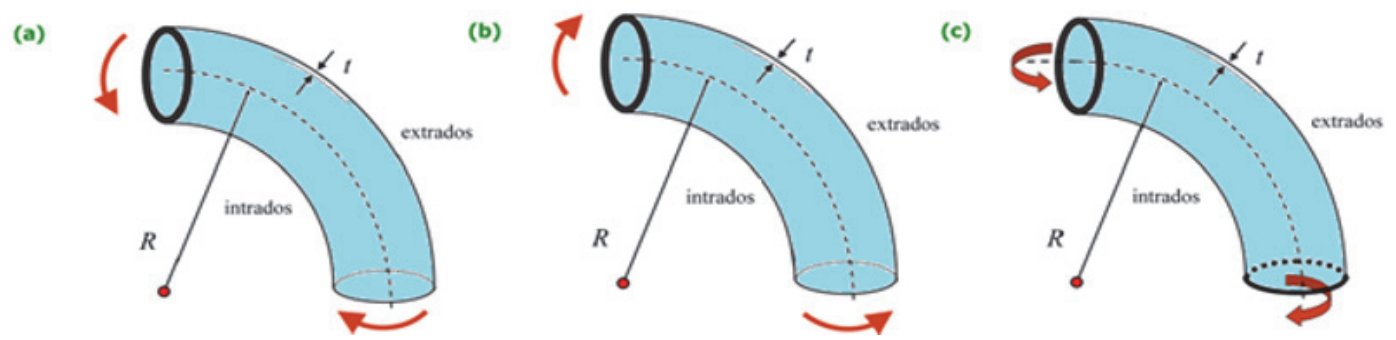

Figure 2: Schematic representation of flexure moment in (a) in-plane closing moments, (b) in-plane opening moments reverse ovalization, and (c) out-of-plane bending

For all the situations studied, the loading conditions are as follows: the attachment is always the same at the end of the linear part of the tube. This consists in fixing the three displacements following ( $x, y$ and $z$ ) and in the other end of the linear part of the tube, a rotation according to the studied case in the direction of opening or closing of the elbow. This rotation takes place around the plane of the structure until its damage, except for the case of moment out plans. It is reported that all the structures studied are under pressure with the presence of temperature in the form of a flow passing through the structure. The properties of the carbon / epoxy are chosen from the experimental work of Auwal Muhammad [32], which allowed us to use these stiffness and resistance parameters. These parameters characterize the architecture of a composite with a $45^{\circ}$ crossover fabric orientation and with helical advancement along the longitudinal axis of the elbow and the straight portions.

\begin{tabular}{|c|c|c|c|c|c|}
\hline $\mathrm{E}_{1}=170000 \mathrm{MPa}$ & $\nu_{12}=0.342$ & $\mathrm{G}_{12}=4800 \mathrm{MPa}$ & $\mathrm{X}^{T}=2050$ & $\mathrm{Y}^{T}=62$ & $\alpha_{11}=0.1 \times 10^{-6} \mathrm{~K}^{-1}$ \\
\hline $\mathrm{E}_{2}=9000 \mathrm{MPa}$ & $\nu_{13}=0.342$ & $\mathrm{G}_{13}=4800 \mathrm{MPa}$ & $X^{C}=1200$ & $Y^{C}=190$ & $\alpha_{22}=0.1 \times 10^{-6} \mathrm{~K}^{-1}$ \\
\hline $\mathrm{E}_{3}=9000 \mathrm{MPa}$ & $v_{23}=0.342$ & $\mathrm{G}_{23}=4500 \mathrm{MPa}$ & $\mathrm{S}^{L}=81$ & $\mathrm{~S}^{T}=81$ & $\alpha_{33}=0.1 \times 10^{-6} \mathrm{~K}^{-1}$ \\
\hline
\end{tabular}

Table 1: For a volume fraction of $65 \%$

E: Young's modulus, v: Poisson's ratio, G: shear modulus, $\alpha$ II: orthotropic expansion [33]

XT: Longitudinal tensile strength, XC: Longitudinal compressive strength, YT: Transverse tensile strength

YC: Transverse compressive strength, SL: Longitudinal shear strength, ST: Transverse shear strength
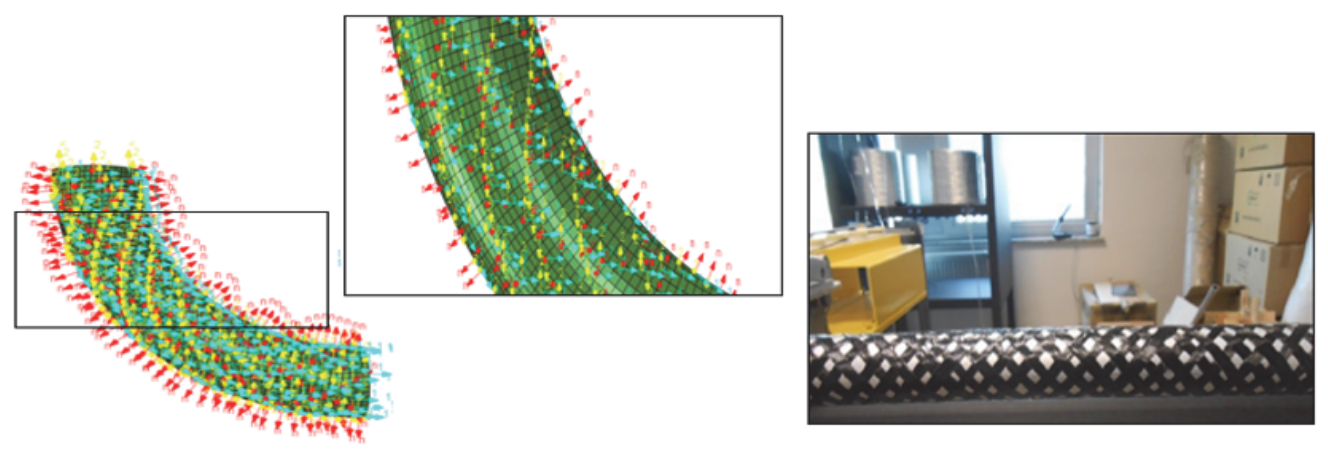

Figure 3: Architecture and Schematizations of the local marks for the composite used [31].

The properties resulting from the experimental used by Auwal Muhammad [32], are for a straight tube. However, for the composite architecture at the elbow, it was provided by a local landmark that follows the curvature of the elbow. To evaluate 
the behavior of our damaged structure, we use "Assigning Material Orientation". This technique can be done either by "Create Geometric Part" or by "Create Mesh Part" in order to sweep the structure by local marks that indicate the orientation of the fibers, see Fig. (3).

The geometric effect of the elbow on the damage of the structure was limited only on the choice of three angles $30^{\circ}, 60^{\circ}$ and $90^{\circ}$ for the same architecture of the composite and each different case (default).

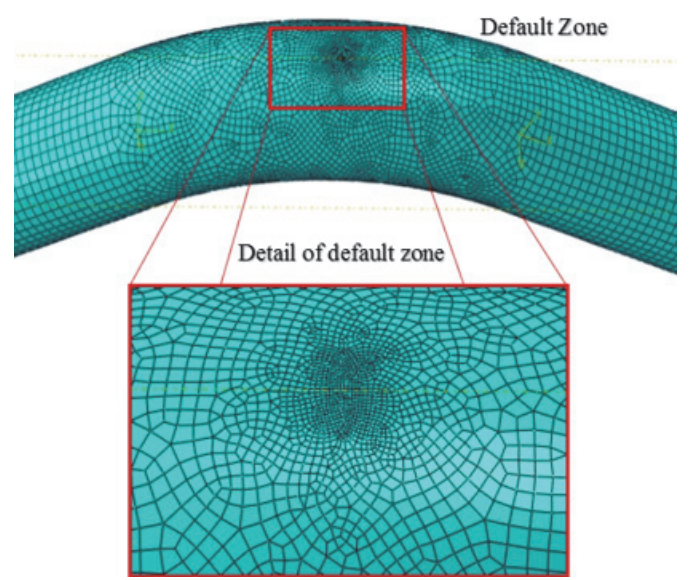

Figure 4: Detail of the mesh of region in elbows of $60^{\circ}$

In this analysis, the mesh of the structure is refined around the defect zone in order to better capture the damage zone in a precise manner. The linear behavior of the composite was presented using S4R shell elements with geometrically zero thickness introduced into the properties of the composite. The number of elements used in the structure depends solely on the angle of the elbow. A number of elements of 8484 is taken for the elbow of $30^{\circ}$ and 9150 elements for the elbow of $60^{\circ}$ and 11270 elements for the elbow of $90^{\circ}$. Fig. (4) shows a detailed example of the mesh used for the calculations.

\section{RESUlTS AND ANALYSIS}

he typical configuration of bends in tubular systems is widely used. The elbows are much more stressed to the loadings than straight tubes hence the importance of studying their behavior and their damage. By the presence of the defects and under the loading in compression and in bending moment, the damage of these elbows is quickly favored. These defects by their quality and their location in certain configurations, condition the level and the mode of the localized damage. Our problematic in this work is to identify the effect of defect in the various cases of figure.
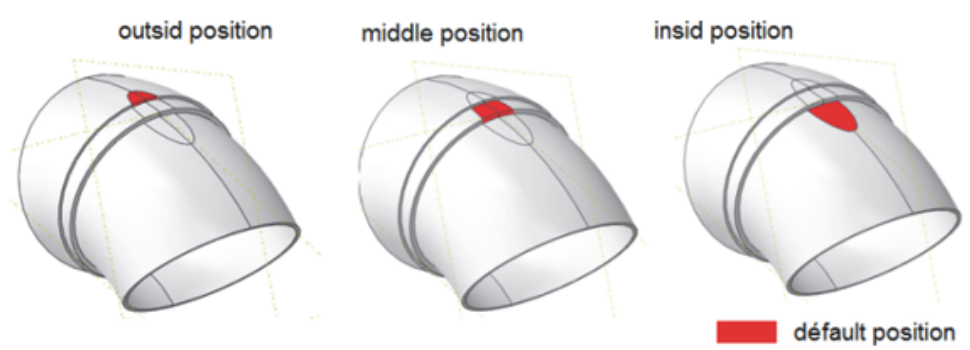

Figure 5: Quality of default in the extrados to the middle of the elbow in $30^{\circ}$.

Our study is to analyze the elbow by three different locations of the defect: in the extrados of the elbow, in the middle or near the end or at the end and by four qualities of defect; the defect according to the whole thickness, half outside or inside and at the end of both sides. Numerically one took several folds with the same orientation of the fibers in order to select the zone of defect to be modified. This modification consists of the cancellation of the continuity of the fibers by a significant decrease of these values of rigidity and resistance. This numerical computation modality has given us the 
advantage with the reliability of creating defects in complex geometric and loading situations without a convergence problem.

a)

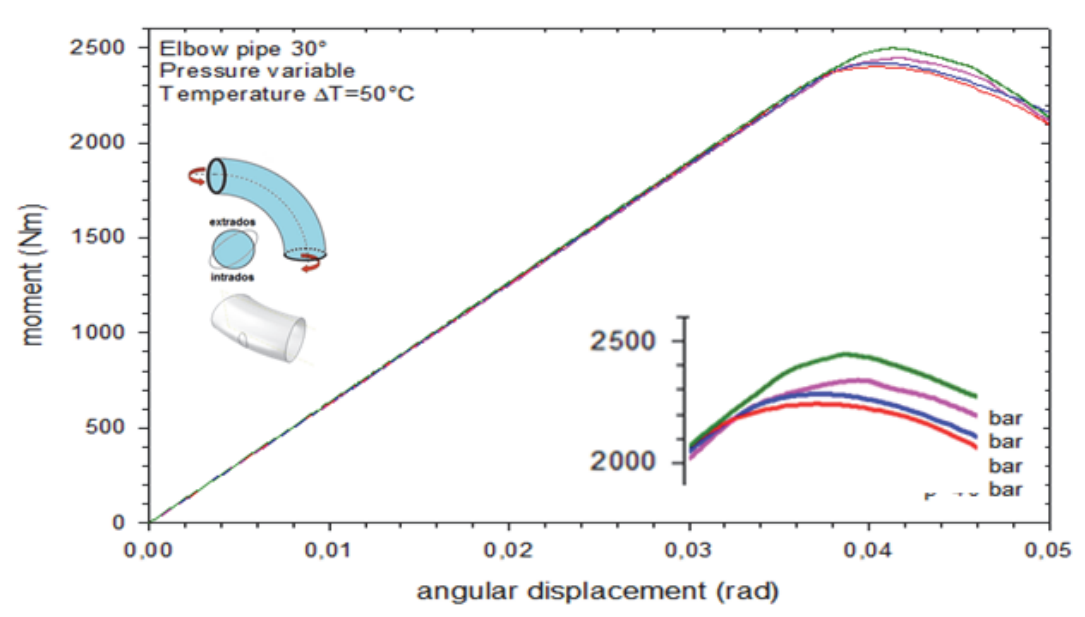

b)

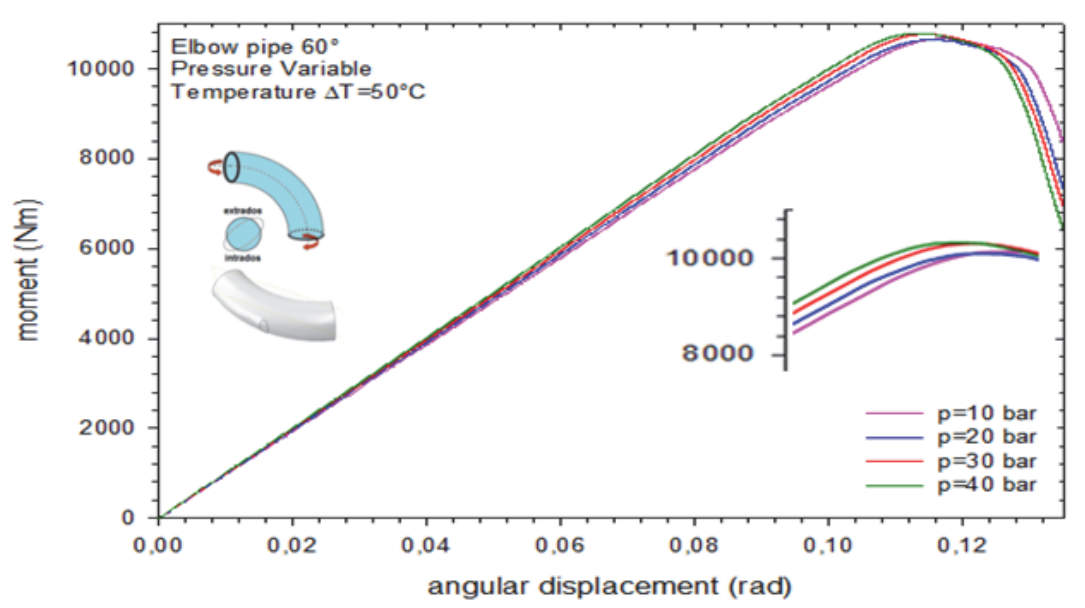

c)

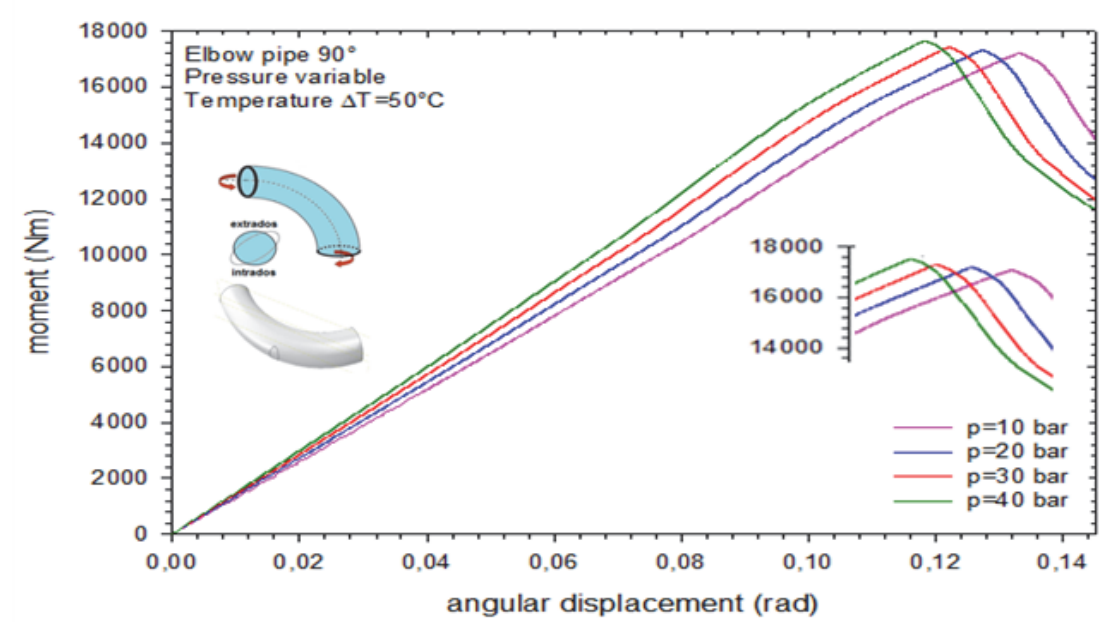

Figure 6: Damage moment-rotation curve with effect of pressure values in the case of all thickness section type and middle default position in a) $30^{\circ}$ b) $60^{\circ}$ c) $90^{\circ}$ angular elbows composite structure under out-of-plane bending moment.

\section{Effect of the pressure with different angular elbows and loading condition on the failure of structure}

The out-of-plane flexural response of a composite elbow is an important research focus in pipe analysis, but with less attention in the literature. Temperature and internal pressure are no longer comparative parameters because they are present 
in all calculations. But depending on the conditions in which they occur, they affect the results. On one side the temperature weakened the structure by accumulating the charges and on the other side the pressure opposes the ovalization. Only the presence of fault conditioned by its quality and location, bending mode and elbow angle, are comparative parameters, hence the resistance capacity of the structure depends on it. The response and the evolution of the system to thermomechanical damage under the evaluative parameters are presented hereinafter by the curves of moments-rotation.

Figs. ( 6 a and b) show that the bend response at bending moment is initially linear and identical for all cases, and take slightly different values just before the maximum moment. This difference is much more caused by the angle of the elbow than by the internal pressure. Figs. (6) also show that during loading, the internal pressure does not delay the damage, in that the bending moment is out of plane. The mode of damage in the out-of-plane bending as shown in Fig. (7), corresponding to a large compression of the matrix on one of the transverse sides of the bend, and tension on the opposite side. The presence of defect has always played the role of amplifying the damage in all the different cases studied.

The out-of-plane bending moment causes twists which later give rise to small, $45^{\circ}$ oriented wrinkles.

This Hashin damage presentation showed us the zone of initiation of damage in compression and tension for the case of fiber and matrix. The dimensionless value 1.00 corresponds to the total damage. In the Hashin criterion, the damage is done by degradation of the rigidity or by the complete suppression of the elements which satisfy the value 1.00 of the structure. It can be seen in all the structures that localized fiber damage occurs only after extensive damage to the matrix in tension and compression. According to the bending mode, the damage is caused either by only the defect (bending in closing) or by the flattening of the cross section of the bend (bending in opening) or by both at the same time as shown in the Figs. (7) (bending out of planes).
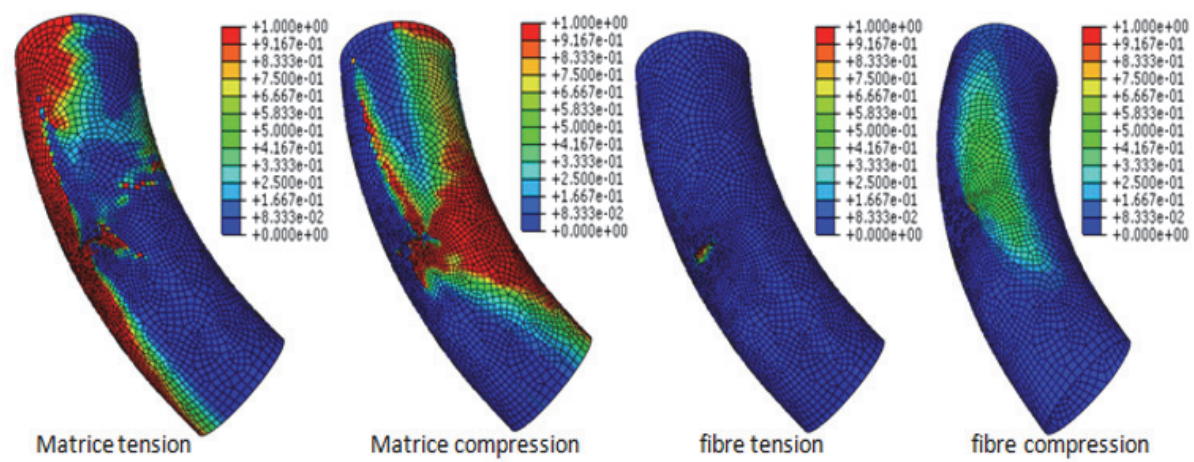

Figure 7: Hashin damage representation in structure with elbows of $60^{\circ}$ under out-of-plane bending moment.

Under the damage by the moment of opening and under the same conditions of internal pressure and temperature, the numerical predictions presented by the Fig. (8) show that the level of damage of the structures is conditioned much more by the type of the moment bending only by the effect of internal pressure and the angle of the elbow. And if we compare the response of the structures to the opening moments, they are very different from those which are submitted to the bending moments out of planes. The response to the bending moments applied is the flattening of the cross section of the bend which takes an orientation in the direction of the bending plane. The mode of elbow failure occurs by a local fiber tension at the central cross section of the elbow. At this point, the critical moment for the 60 and $90^{\circ}$ elbows is $52^{\circ} \%$ and $28 \%$ less than the $30^{\circ}$ elbow, respectively, see Fig. (8). There is a very weak pressure effect dominated by the rigidity of the composite that appears weakly for structures with a $90^{\circ}$ elbow. This effect on response increases as the moment approaches its critical value, as shown in Fig. (8-c). Load responses have almost the same trends as in Fig. (6).

It is found in Fig. (10) the same responses up to the critical moment with slightly different levels for the three bends of $30^{\circ}$, $60^{\circ}$ and $90^{\circ}$. The structure with the $30^{\circ}$ elbow allows a large deformation capacity and a very low pressure effect. Excessive ovality is observed in the case where the structure is subjected to closing bending moments. The flattening is perpendicular to the plane of flexion. The response to the loading of structures leads to the mechanism of their rapid damage due to the additive effect of applied temperature. Failure, therefore, occurs when the composite is solicited by its matrix at high voltages at the extrados of the elbow and by these fibers in tension at the finely localized defect. Localized damage caused by defect positioning may not occur, or with the effect of pressure and temperature. This is illustrated in Fig. (11). The presence of internal pressure has a positive effect on the flexural deformation capacity; it allows the deformation in rotation without breaking because it prevents the structure from becoming ovalized, may remain very weak by the fact that the composite behaves linearly until it is damaged. 
a)

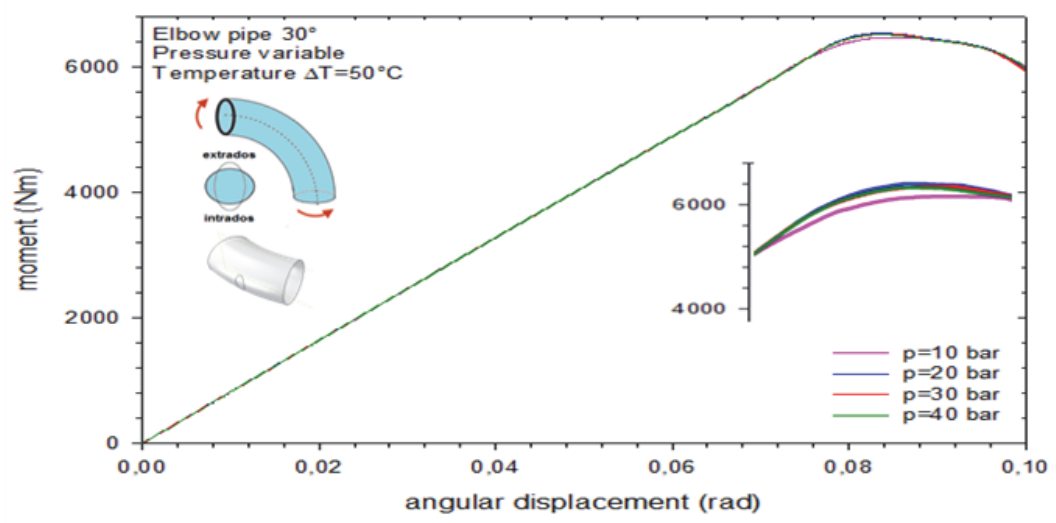

b)

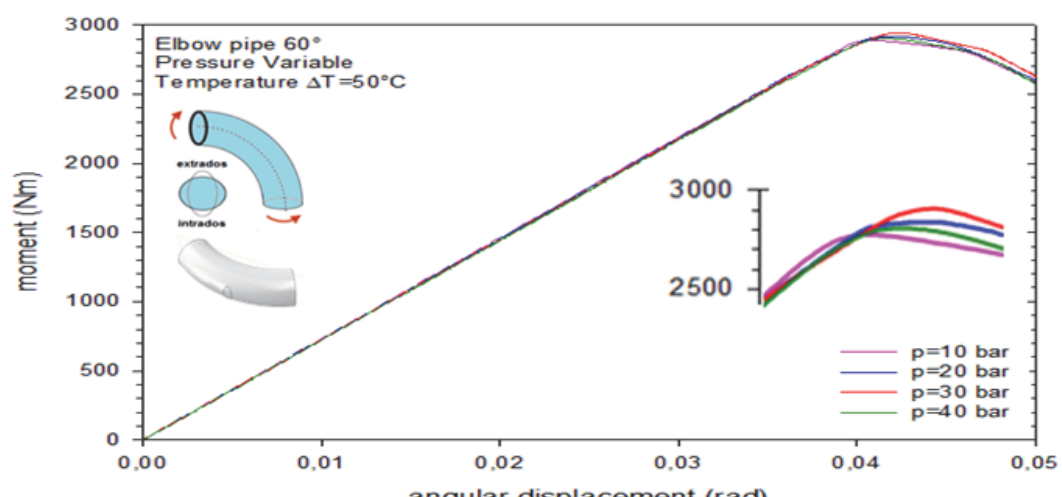

c)

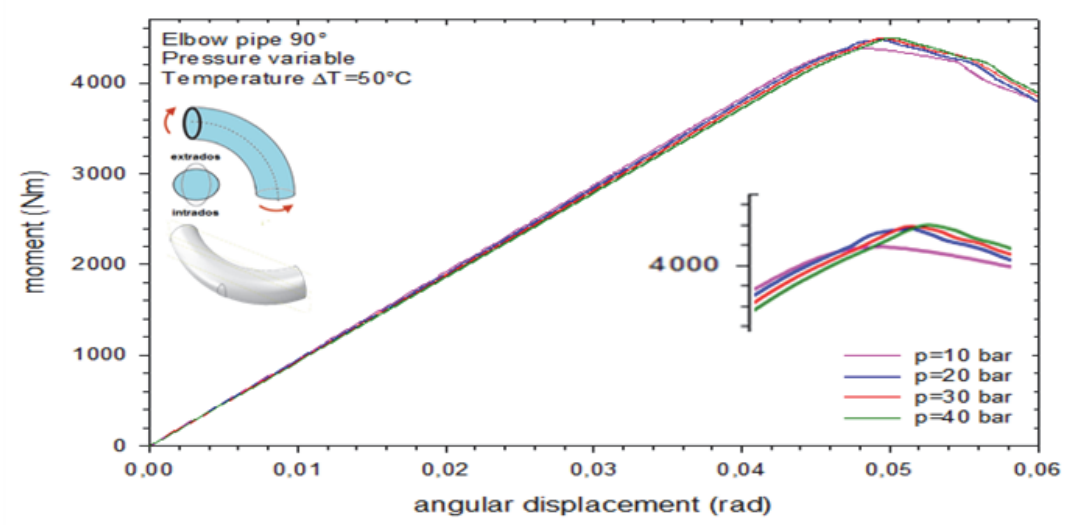

Figure 8: damage moment-rotation curve with effect of pressure values in the case of all thickness section type and middle default position in a) $30^{\circ}$ b) $60^{\circ}$ c) $90^{\circ}$ angular elbows composite structure under opening moment.

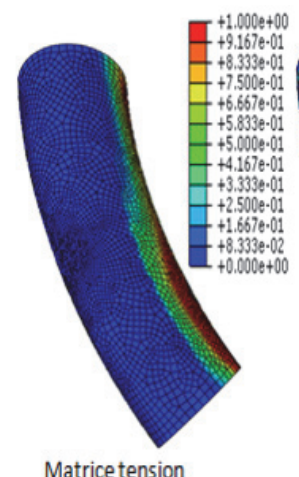

Matrice tension

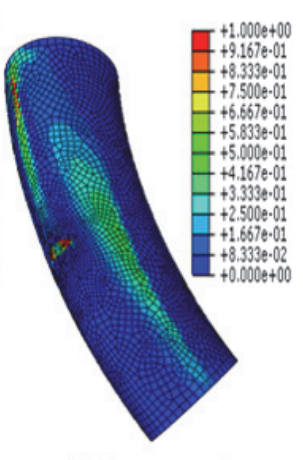

Matrice compression

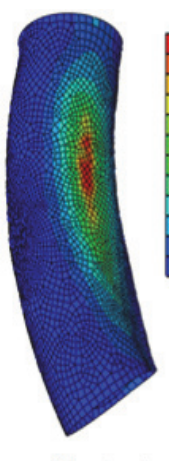

fibre tension

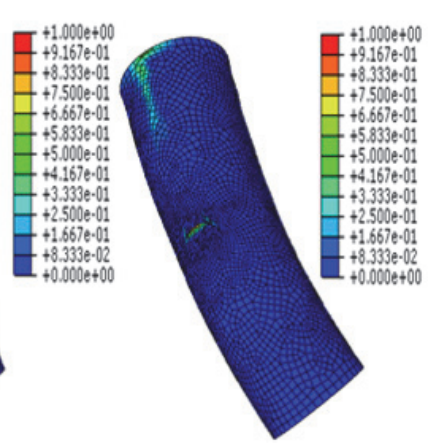

fibre compression

Figure 9: Hashin damage representation in structure with elbows of $60^{\circ}$ under opening moment. 
a)

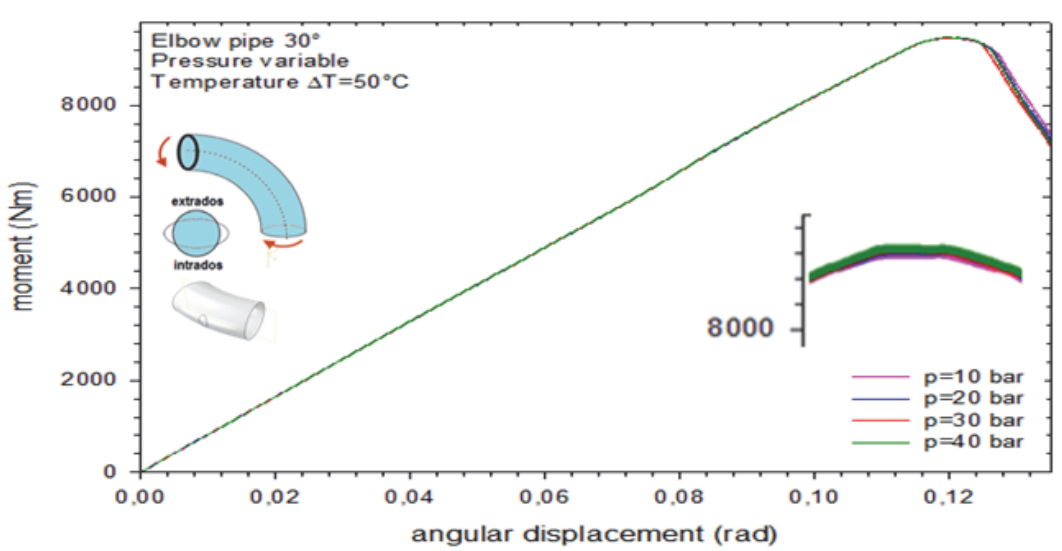

b)

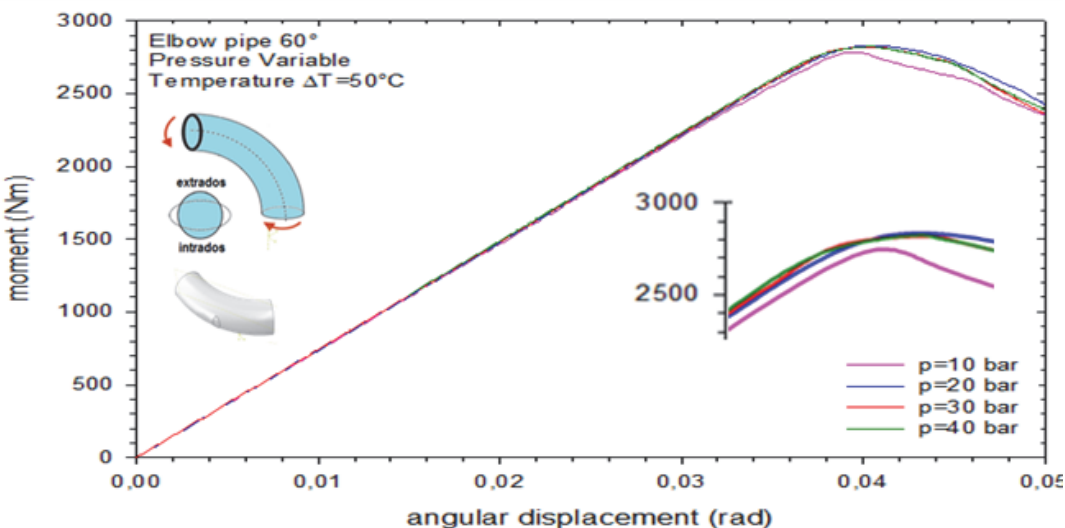

c)

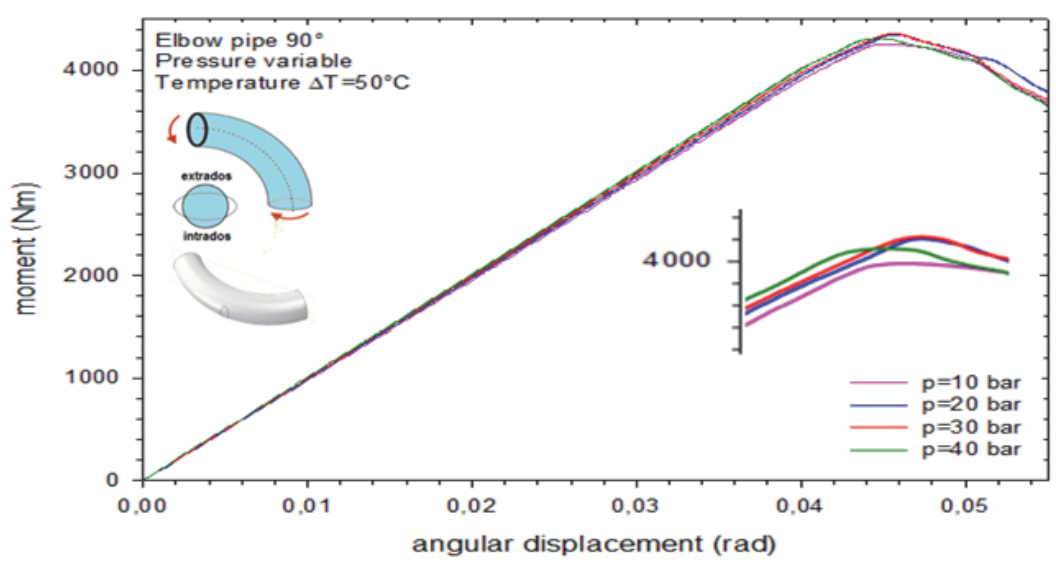

Figure 10: Damage moment-rotation curve with effect of pressure values in the case of all thickness section type and middle default position in a) $30^{\circ}$ b) $60^{\circ}$ c) $90^{\circ}$ angular elbows composite structure under closing moment.
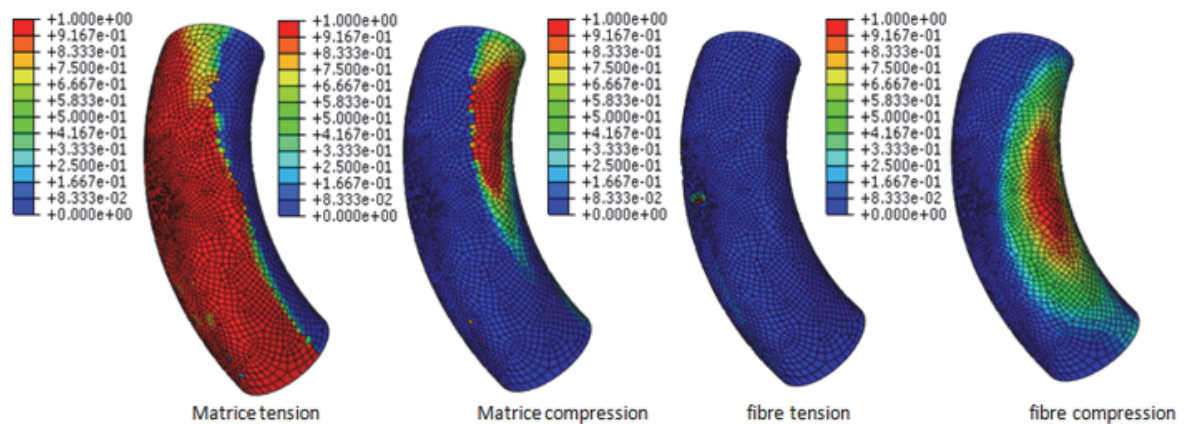

Figure 11: Hashin damage representation in structure with elbows of $60^{\circ}$ under closing moment 
In order to better compare and group all the effects and their interdependence on the critical bending moment of each situation, this Fig. (12) has been recapitulated under the condition of the same levels of internal pressure and applied temperature. The composite structure does not allow large deformations (ovalization), hence the weak effect of the internal pressure in certain situations. By purely geometrical effect of the elbows and their ovalization in their cross section, the fibers of the composite are subjected locally to the tensions and others to the compressions. The damage to the elbow is more conditioned by the angle than by the bending mode, hence the critical moments observed in the structure with a $30^{\circ}$ elbow. Add to this the effect of location of the defect that approaches critical areas of the elbow (tension or compression).

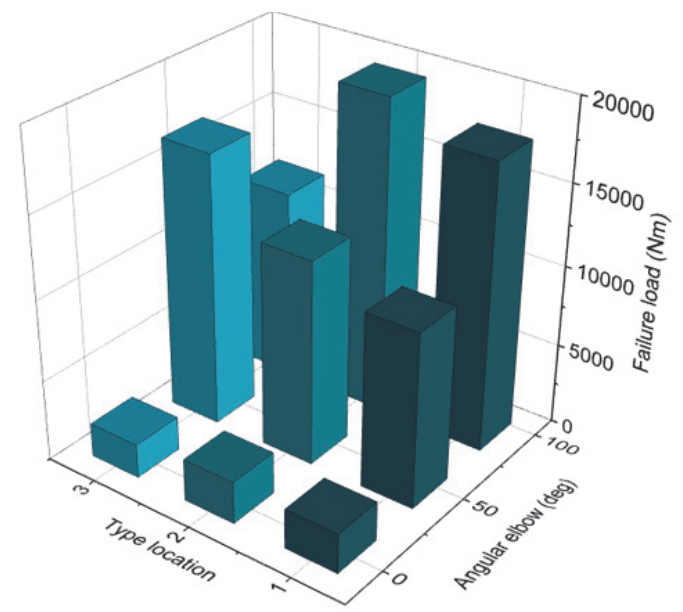

a)

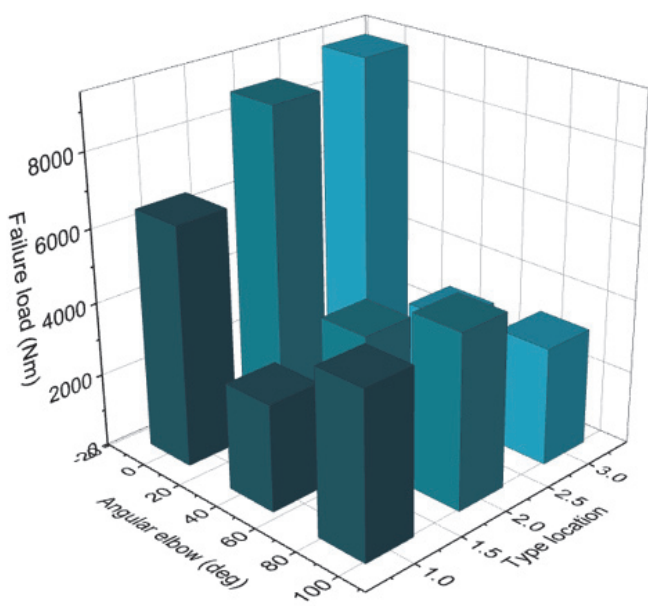

b)

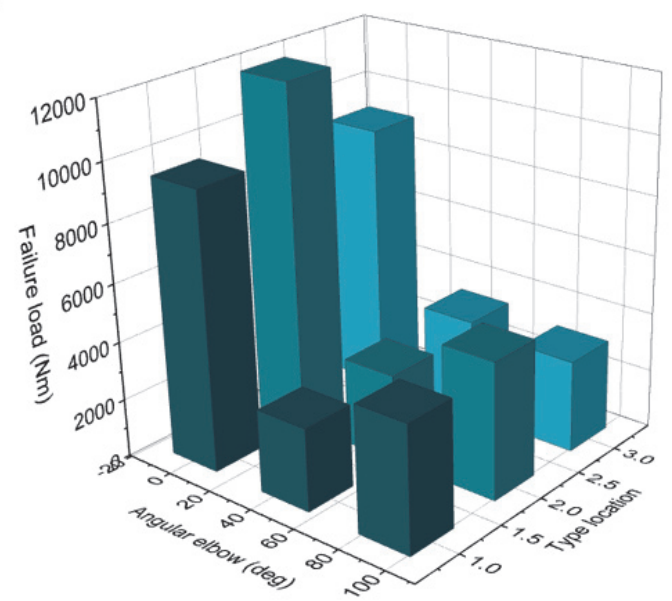

c)

Figure 12: Recapitulative of damage in a) out-of-plane bending moment, b) opening moment, c) closing moment with effect of angular elbows composite structure and default position under thermo-mechanical loaded condition.

\section{Effect of the emplacement and default type with different angular elbows and loading conditions on the failure of structure}

In this part of this study, our work focuses on the response to the damage of various structures by effect of location and quality of defect under the presence of temperature and internal pressure. The presence of defect in itself has a significant effect according to the conditions of our structures in which they are subjected. According to the composite used in its architecture presented by these break parameters that allow several modes of failure, the defect took throughout this study a single form with a single dimension $(\mathrm{a} / \mathrm{b})$

$=(6 / 3)$. The defect zone was presented by a low resistance to damage, which has the effect of destabilizing the structure differently in three selected locations; that in extrados of the elbow in the middle (type 1) near the end (type 2) and at its end (type3). The quality of the defect is illustrated in the Fig. (5) which is presented only according to the thickness by: the defect is following the whole thickness, the half outside or inside and with the end of both sides.

The causes of damage in the presence of a defect in the composites of our structure subjected to both the internal pressure and the bending moment are manifold. The effect of defect quality is important under torsion caused by out-of-plane bending moment. The thickness of the elbow is heavily stressed in tension and compression, hence the effect of defect 
quality which results in critical moment values up to $200 \mathrm{Nm}$ difference. Fig. (13) shows that in the case where the defect is in the middle of the thickness of the elbow, failure is more favored. This one is much more stressed with the torsion forces which damage the fibers after the total damage of the matrix of the composite than in the case where the defect is in the free surface. Because the latter is absorbed by the angular displacements. The effect of the location of defects on the response and the critical moment in bending out of planes depends on the approach towards the zones of tension or excessive compression from where the disordered one illustrated in the Fig. (13).

a)

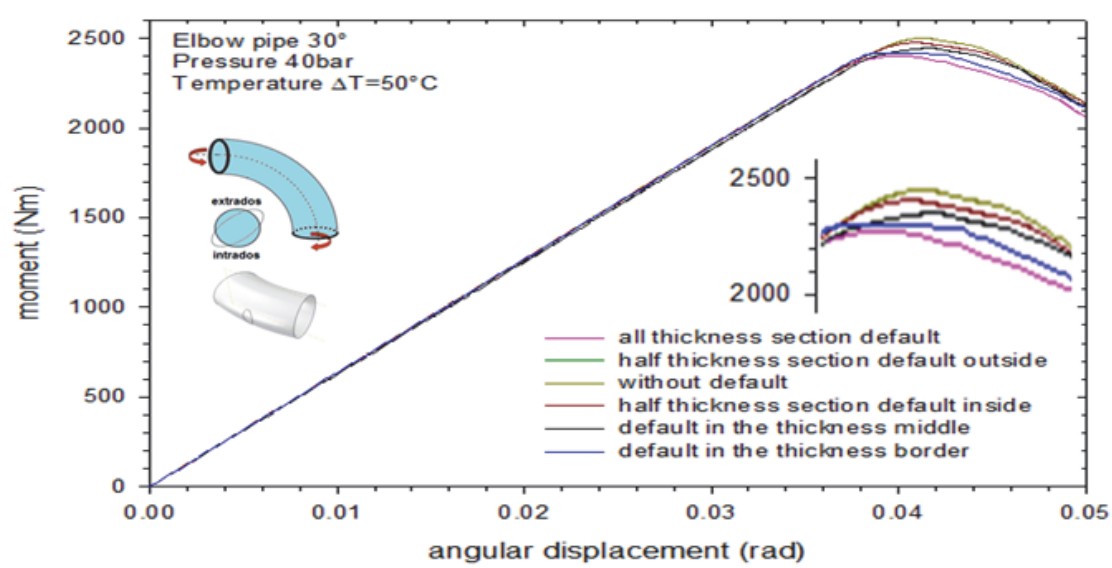

b)

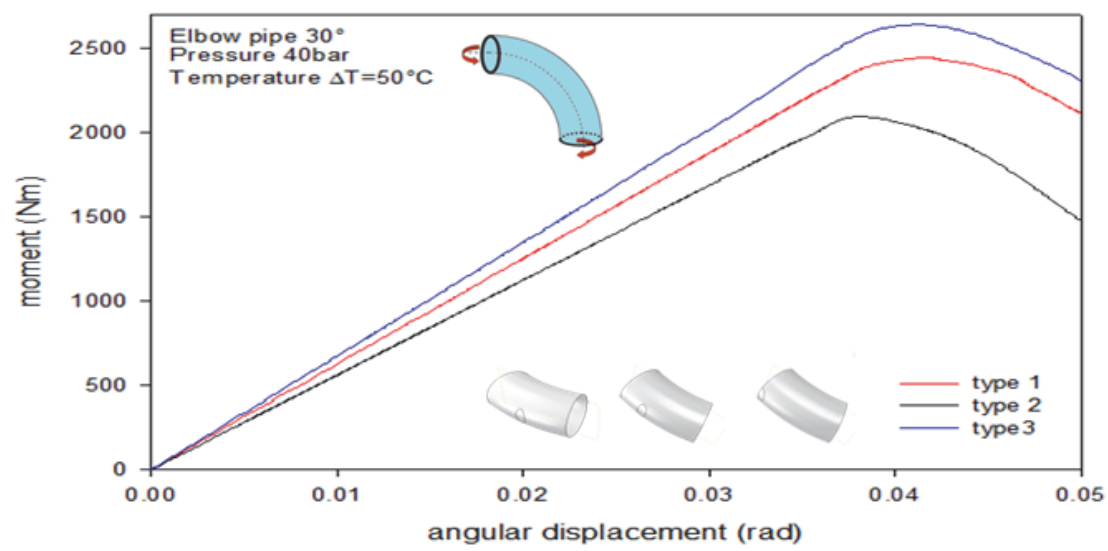

Figure 13: Damage moment-rotation curve under hors plans moment in the case of a) middle position with effect of their type and in the case of b) all thickness section default with effect of their position.

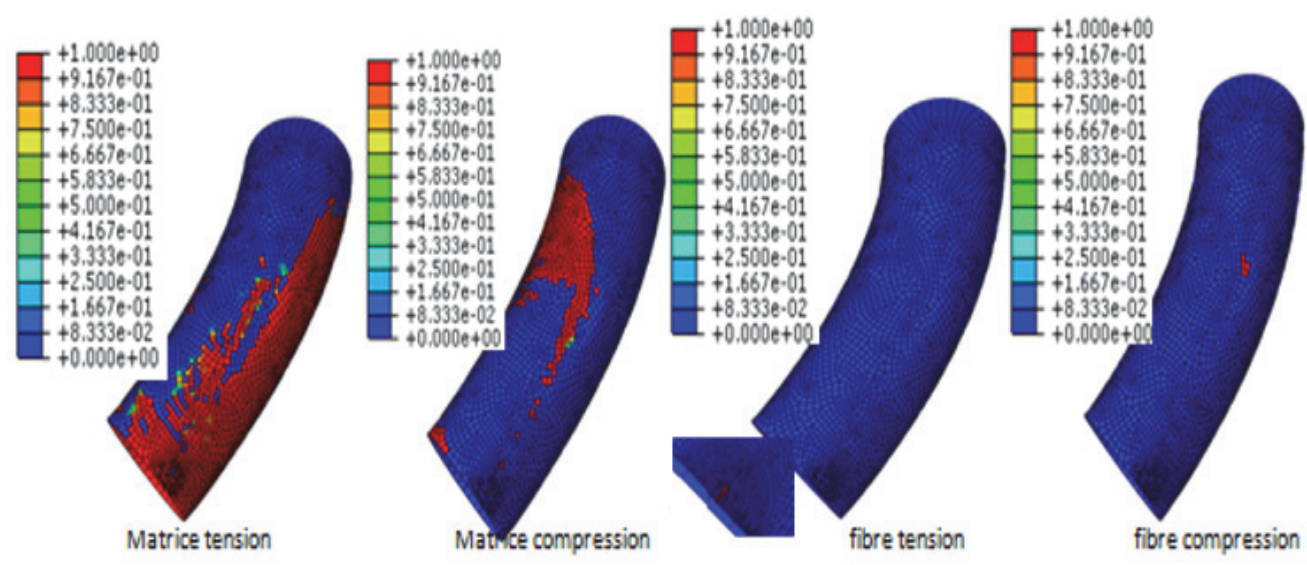

Figure 14: Hashin damage representation in structure with elbows of $60^{\circ}$ under hors plans moment, type (3). 
a)

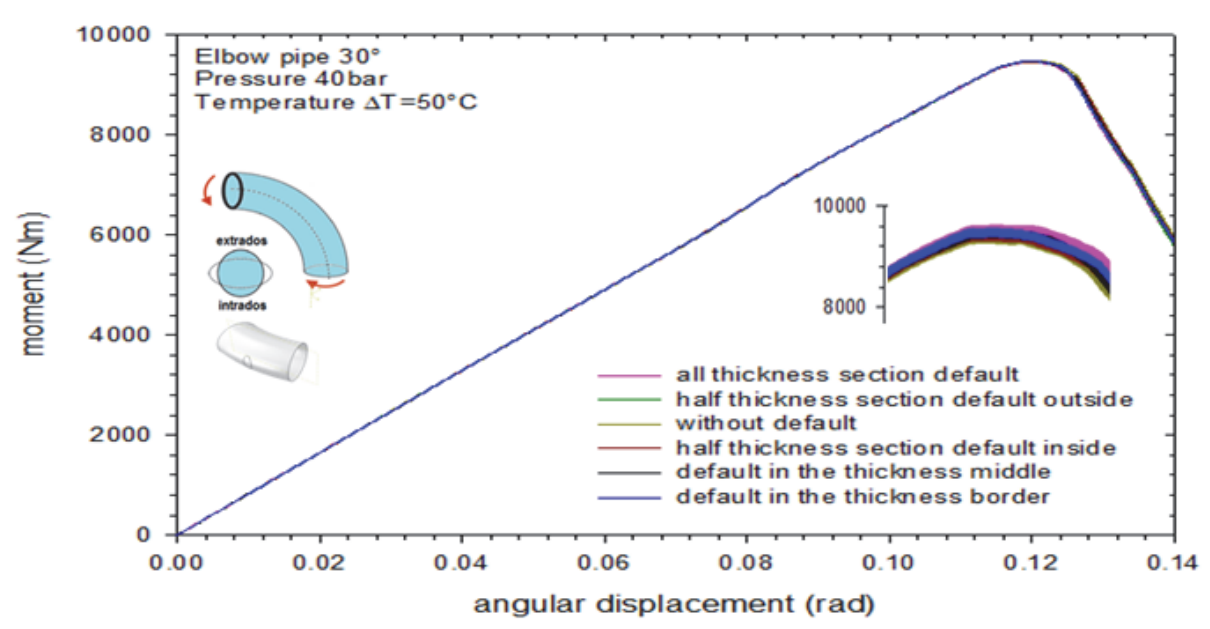

b)

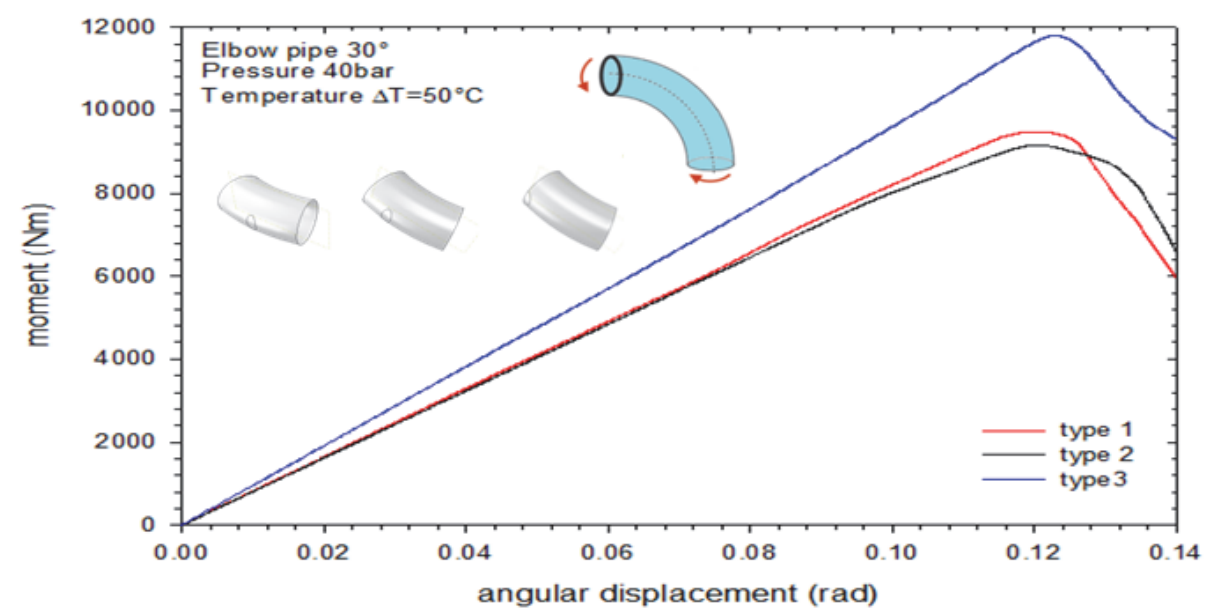

Figure 15: Damage moment-rotation curve under closing moment in the case of a) middle position with effect of their type and in the case of b) all thickness section default with effect of their position

The defect quality effect is conditioned by its location, in the case of closing bending moment as the opening case, its quality does not have much influence on the level and the structure response up to their damage. This situation is explained by the concentration of efforts on this area. By the fact that the defect is always at these locations in the extrados of the elbow, its dangerousness increase according to the mode of bending, in other words the fibers of the composite are in tension or in excessive compression by the ovalization of the elbow. These fibers will strongly react with the approximation of defects, which is the case for the closing bending moment, particularly the defect in the middle and the one near the end of the elbow or the critical moment's levels. Is weak with a value close to $9000 \mathrm{Nm}$.

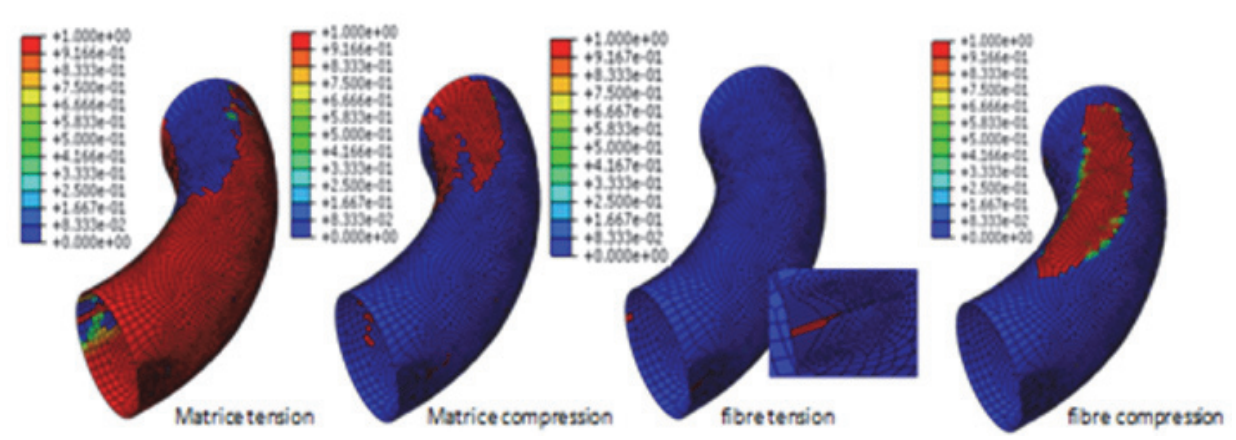

Figure 16: Hashin damage representation in structure with elbows of $60^{\circ}$ under closing moment, type (3) 
a)

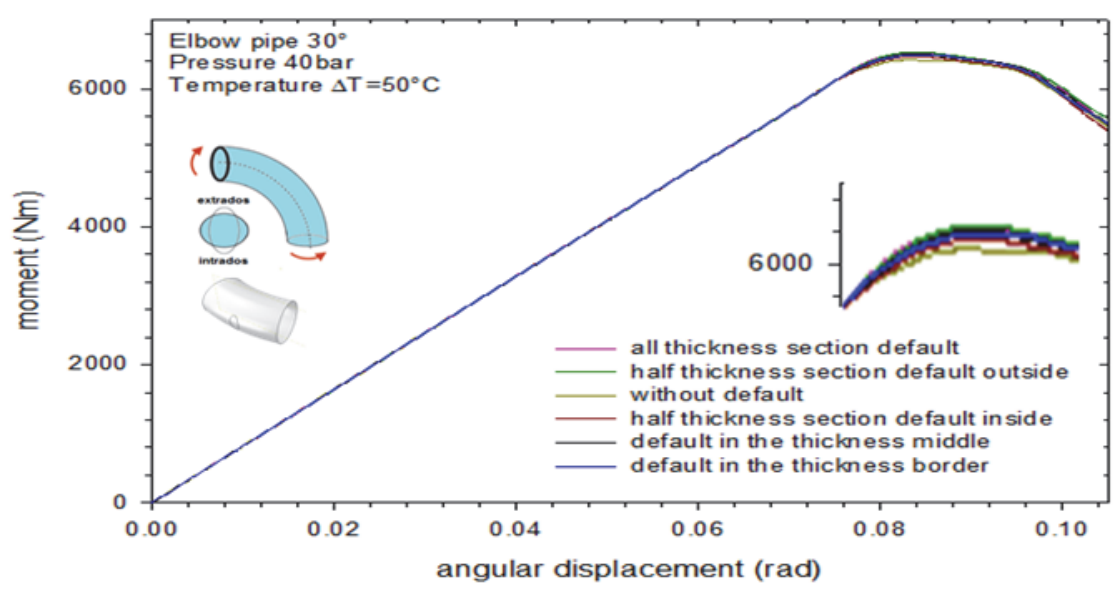

b)

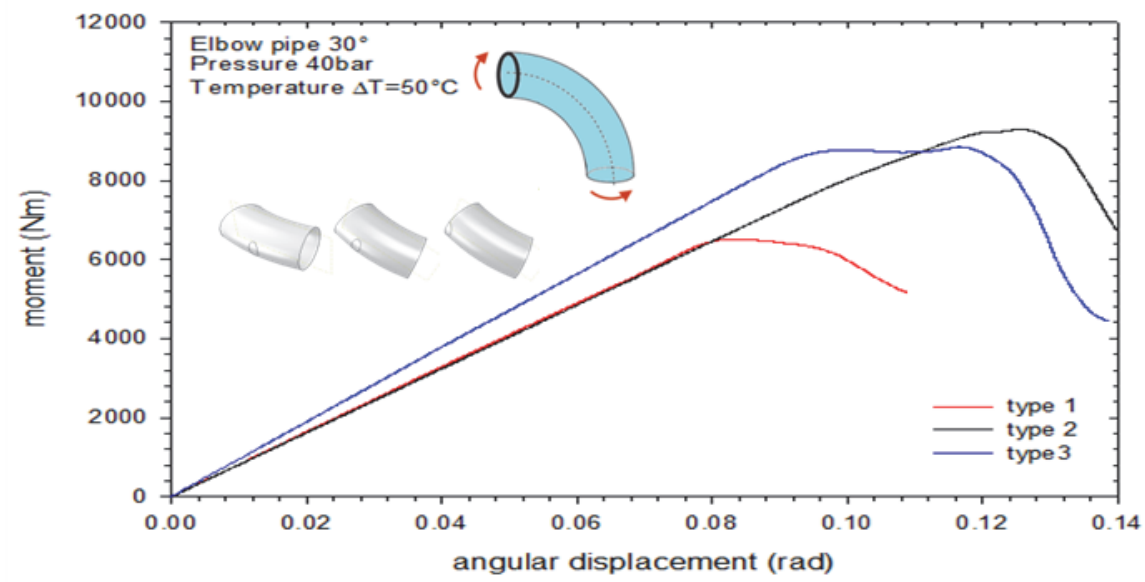

Figure 17: Damage moment-rotation curve under opening moment in the case of a) middle position with effect of their type and in the case of b) all thickness section default with effect of their position.

As in the previous section, in the case of closing bending moment, the effect of defect quality is not important. The same response is always obtained with the same level of critical moment of flexion in opening. The defect by its position is always stressed in excessive compression, which is why the damage occurs at low values of the critical moment. Fig. (17) shows that the defect location in the composite elbow with the presence of pressure and that of temperature has a significant effect on the structure response and on the critical moment level for damage to the moment case. Bending in opening, with values shifted up to $3000 \mathrm{Nm}$.

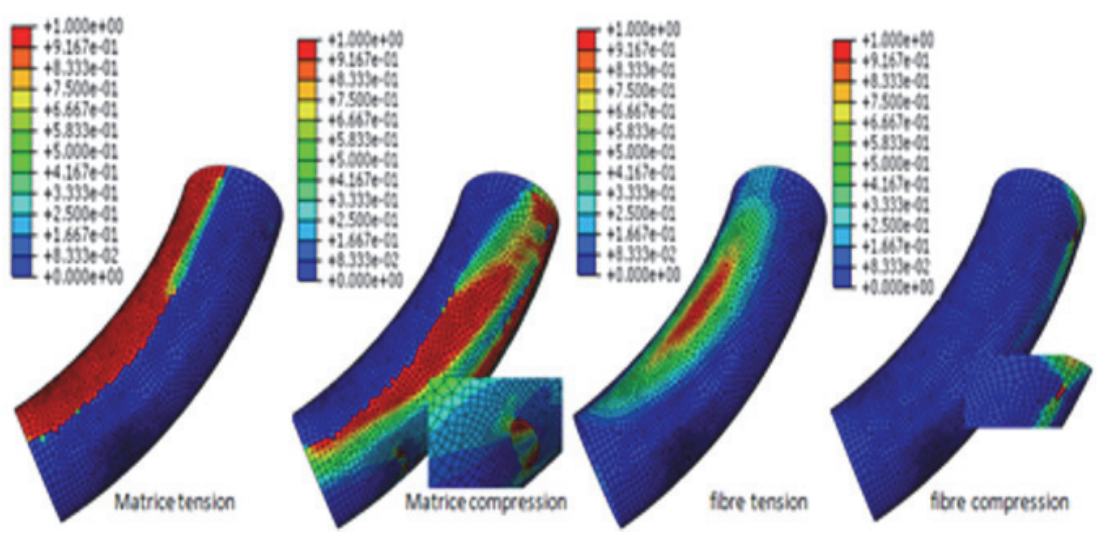

Figure 18: Hashin damage representation in structure with elbows of $60^{\circ}$ under opening moment, type (2). 


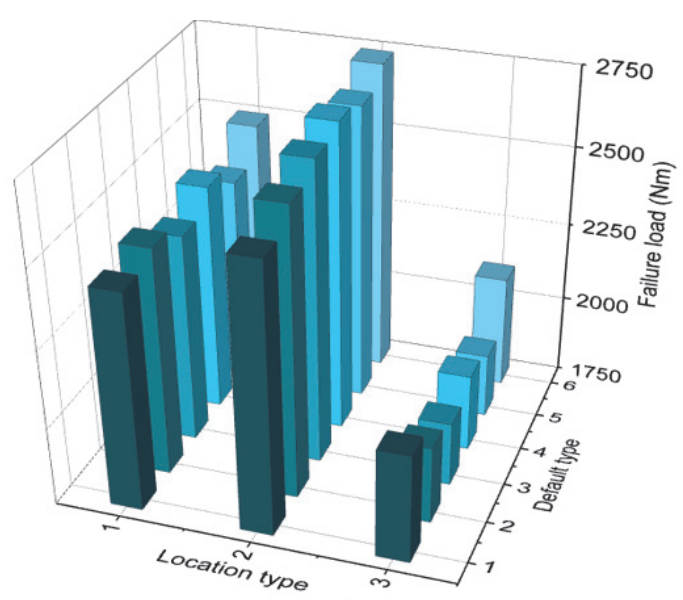

a)

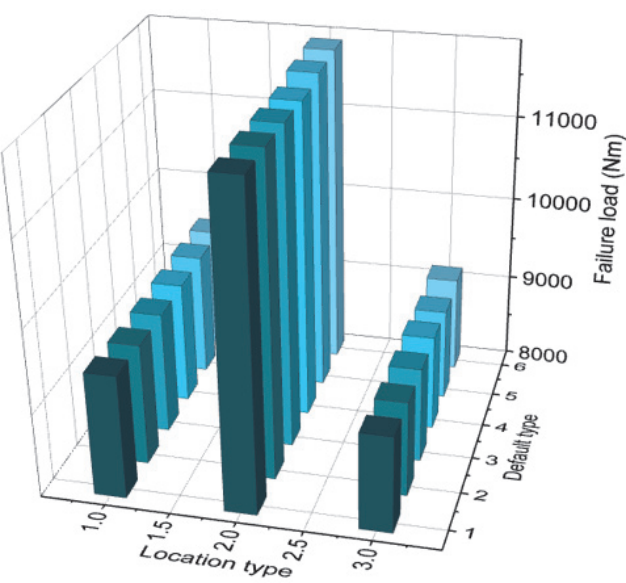

b)

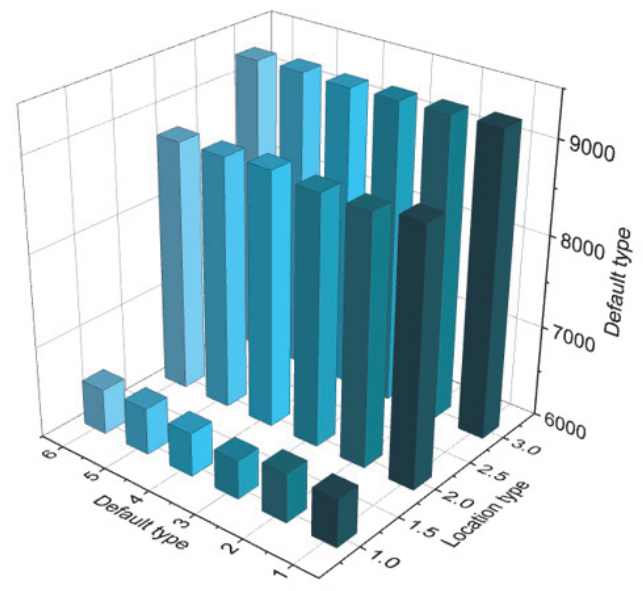

c)

Figure 19: Damage recapitulative in a) hors plans moment b) opening moment c) closing moment in elbows composite structure with effect of default types and their position under thermomechanical loaded condition.

Fig. (19) presents a series of calculations made for different cases of structure, under the same levels of internal pressure and applied temperature. A summary takes place to clarify the effect of both location and quality of defect on the critical moment of each situation. The structure beneath the out-of-plane bending moment shows that the defect quality effect appears slightly in each location, which is not the case for the other two situations of bending moment (in closing and opening), where the quality effect is the same. In all three bending modes, the location has a critical time effect. This effect occurs with significant levels for the fault location near the end, which is where critical areas of tension or fiber compression in the $30^{\circ}$ elbow occur.

\section{CONCLUSION}

his work has well presented the effectiveness of the damage criterion under complex geometric and loading conditions and in composite structures of a tubular model connected by elbow in the middle. The results obtained allowed us to evaluate and compare various parameters influencing the damage of our structure to study.

- The Hashin criterion technique was used to estimate the critical moment value of the composite pipeline structure under thermomechanical behavior using shell elements

- Pressurized tubular composite structures can support the same loading with different deformation capabilities.

- The presence of a defect aggravates the damage by its quality and is location and following the mode of bending moment applied. In the tubular structures the internal pressure opposes the ovalization during loading in bending moment.

- The bending mode undergone by the elbow conditions the ovalization planes and its capacity supported by the fibers is dependent on the angle of the elbow. 
- The fault approach to areas of ovalization of tension or compression locates and quickly promotes damage to the elbow.

- The deformation in most of the studied structures occurs strongly and rapidly by temperature effect at two locations caused by the flattening of the cross-section.

\section{REFERENCES}

[1] American Society of Mechanical Engineers, 2007, Factory-Made Wrought Buttwelding Fittings, B16.9, ASME, New York.

[2] American Society of Mechanical Engineers, 2010, Power Piping, B31.1, ASME, New York.

[3] American Society of Mechanical Engineers, 2010, Process Piping, B31.3, ASME, New York.

[4] Comité Européen de Normalisation, 2002, "Metallic Industrial Piping-Part 3 : Design and Calculation," Standard EN 13480-3, Brussels, Belgium.

[5] Lee, S. H., and Wass, A. M. (1999). Compressive Response and Failure of Fiber Reinforced Unidirectional Composites, International Journal of Fracture, 100, pp. 275 - 306.

[6] Palanivelu, S., Paepegem, W., Degrieck, J., Vantomme, J., Kakogiannis, D., Ackeren, J., Hemelrijik, D. and Wastiels, J. (2011). Crushing and Energy Absorption Performance of Different Geometrical Shapes of Small - Scale Glass Polyester Composite Tubes under Quasi Static Loading Conditions, Composite Structures, 93, pp. 992 - 1007.

[7] Natsuki, T., Takayamagi, H., Tsuda, H. and Kemmochi, K., (2003). Prediction of Bending Strength for Filament-Wound Composite Pipes, Journal of Reinforced Plastics and Composites, 22, pp. 695-710

[8] Kitching, R., Myler, P. and Tan, A.L. (1998). GRP Pipe Bends Subjected to Out-of-plane Flexure with and without Pressure,Journal of Strain Analysis, 23(4), pp. 187-199.

[9] Kochekseraii, S.B. and Robinson, M., (2004). Flexural Behaviour of a Polyvinyl Chloride- lined Glass-Reinforced Plastic Composite multi-Mitred Pipe Bend Subjected to Combined Loads: A Comparative Finite Element Analysis and Experimental Case Study, Journal of Strain Analysis, 39(2), pp. 137-146.

[10] Camilleri, D., Ellul, B., Muscat, M. (2014). Design-by-analysis Methods for Asymmetric or Unbalanced Cylindrical Composite Pressure Vessels, Proceedings of the ASME PVP2014, PVP2014-28130, Anaheim, California, USA.

[11] Shao, Z. S., (2005). Mechanical and Thermal Stresses of a Functionally Graded Circular Hollow Cylinder With Finite Length, Int. J. Pressure Vessels Piping, 82(3), pp. 155-163.

[12] Kandil, A., El-Kady, A. A., and El-Kafrawy, A. (1995), Transient Thermal Stress Analysis of Thick-Walled Cylinders, Int. J. Mech. Sci., 37(7), pp. 721-732.

[13] Bakaiyan, H., Hosseini, H. and Ameri, E. (2009). Analysis of Multi-Layered Filament Wound Composite Pipes under Combined Internal Pressure and Thermomechanical Loading with Thermal Variations, Composite Structures, 88, pp. 532- 541.

[14] Ansari, R., Alisafaei, F., and Ghaedi, P. (2010). Dynamic Analysis of Multi-layered Filament Wound Composite Pipes Subjected to Cyclic Internal Pressure and Cyclic Temperature, Composite Structures, 92, pp. 1100-1109.

[15] Xia, M., Kemmochi, K. and Takayanagi, H. (2016). Analysis of Filament-Wound Fiber- reinforced Sandwich Pipe under Combined Internal Pressure and Thermomechanical Loading, Composite Structures, 51, 3, 273-283.

[16] Kubo, S. (1992), Inverse Problem, Baifukan, Tokyo (in Japanese).

[17] Kim, S. H., Park, C. H. (2017). Direct impregnation of thermoplastic melt into flax textile reinforcement for semistructural composite parts, Industrial Crops and Products 95, pp. 651-663.

[18] Andersons, J., König, M. (2004). Dependence of fracture toughness of composite laminates on interface ply orientations and delamination growth direction. Composites Science and Technology. 64, pp. 2139-2152.

[19] Wimmer, G., Schuecker, C., Pettermann, H.E. (2009). Numerical simulation of delamination in laminated composite components - A combination of a strength criterion and fracture mechanics. Composites Part B: Engineering. 40, pp. 158-165.

[20] Wimmer, G., Pettermann H.E. (2009). Prediction of Delamination Growth in Laminated Structures Loaded by Quasistatic and Cyclic Loads. Journal of Composite Materials. 43, pp. 3303-3324.

[21] Gözlüklü, B, Coker, D. (2012). Modeling of the dynamic delamination of L-shaped unidirectional laminated composites. Composite Structures. 94, pp. 1430-1442.

[22] Gözlüklü, B. (2014). Modeling of intersonic delamination in curved-thick composite laminates under quasi-stastic loading [PhD]: Middle east technical university.

[23] Garnish, M.R., and Akula, V.M.K. (2008). Review of Degradation Models for Progressive Failure Analysis of Fiber Reinforced Polymer Composites, ASME Appl. Mech. Rev., 62(1), 010801-33 
[24] Padhi, G.S., Shenoi, R.A., Moy, S.S.J. and Hawkins, G. L. (1998). Progressive Failure and Ultimate Collapse of Laminated Composite Plates in Bending, Composite Structures, 40(3-4), pp. 277-291.

[25] Tsai, S.W., and Wu, E.M., (1971). A General theory of Strength for Anisotropic Materials, Journal of Computation Materials, 5(1), pp. 58-80.

[26] Barbero, E. J., Shahbazi, M. (2017). Determination of Material Properties for ANSYS Progressive Damage Analysis of Laminated Composites"; Composite Structures 176, pp. 768-779.

[27] Ellul, B., Camilleri, D., (2015). The Influence of Manufacturing Variances on the Progressive Failure of Filament Wound Cylindrical Pressure Vessels, Composite Structures, 133, pp. 853-862

[28] Davila, C. G., Camanho, P. P. and Rose, C. A. (2005). Failure Criteria for FRP Laminates, Journal of Composite Materials, 39(4).

[29] ABAQUS user manuals, 1 - 3, (2014).

[30] Sokolinsky, V. (2013). Using Failure Criteria for Unidirectional Fiber Composite in Abaqus, Simulia.

[31] Spyros A. Karamanos, (2016). Mechanical Behavior of Steel Pipe Bends: An Overview, Journal of Pressure Vessel Technology, 138 / 041203-1

[32] Auwal, M., Ercan, Ş. (2014). Experimental and Numerical Study of Energy Absorption Behaviour of Glass and Carbon Epoxy Composite Tubes under Static Compressive Loading IOSR Journal of Applied Physics (IOSR-JAP) 6(4), pp- 3037.

[33] Tous les matériaux pour la Recherche, l’Industrie et la Production “http://www. goodfellow.com”, 15/01/2019. 